DOI: https://doi.org/10.30749/2177-8337.v24n48p146-171

\title{
DIREITOS FUNDAMENTAIS SOBRE UMA PERSPECTIVA DE LIBERDADE
}

\section{FUNDAMENTAL RIGHTS FROM THE PERSPECTIVE OF FREEDOM}

\author{
Bruno Laércio de Melo* \\ Rafael Lazzarotto Simioni**
}

\begin{abstract}
Resumo: $O$ presente trabalho tem por objetivo o estudo dos direitos fundamentais em perspectiva de acesso a liberdades que são ofertados em um paradigma de um Estado democrático. A pobreza e a desigualdade social tem sido o grande desafio de nações subdesenvolvidas e em especial do Brasil. Frente a uma onda neoliberal que em muitas ocasiões propõe a mínima intervenção do Estado, o trabalho tem por objetivo analisar a importância da intervenção estatal através das políticas públicas. Diante de uma iminente alteração normativa e sociológica no Brasil, este trabalho demonstra sua atualidade e importância. Possui como problemática a análise através de um paralelo entre o sistema de saúde e de educação no Brasil antes e depois da Constituição de 1988. A estruturação desse trabalho se faz sobre a metodologia de revisão bibliográfica com abordagem exploratória.
\end{abstract}

Palavras-chave: Democracia. Desenvolvimento social. Neoliberalismo. Estado de bem-estar social. Brasil.

Abstract: This paper aims to study fundamental rights in terms of access to freedoms that are offered in a paradigm of a democratic state. Poverty and social inequality have been the great challenge for underdeveloped nations and especially for Brazil. Faced with a neoliberal wave that on many occasions proposes minimal State intervention, the work aims to analyze the importance of state intervention through public policies. Faced with an imminent normative and sociological change in Brazil, this work demonstrates its timeliness and importance. It has as problematic the analysis through a parallel between the health and education system in Brazil before and after the 1988 Constitution. This work is structured on the methodology of bibliographic review with an exploratory approach.

Keywords: Democracy. Social development. Neoliberalism. Welfare state. Brazil.

Recebido em: $27 / 03 / 2020$

Aceito em: 22/06/2020

\footnotetext{
* Mestrando em Direito pela Faculdade de Direito do Sul de Minas (FDSM), com especialização em andamento em Direito Público pela Escola Paulista de Direito (EPD). E-mail: brunopa2000@gmail.com. ** Doutor em Direito Público pela Universidade do Vale do Rio dos Sinos (Unisinos), Mestre em Direito pela Universidade de Caxias do Sul (UCS), Professor do Programa de Mestrado em Direito da Faculdade de Direito do Sul de Minas (FDSM) e do Programa de Mestrado em Bioética da Universidade do Vale do Sapucaí (Univás), Pesquisador-Líder do Grupo de Pesquisa Margens do Direito (PPGD/FDSM).
} 


\section{INTRODUÇÃO}

A pobreza e a miséria têm sido um grande desafio a ser vencido pelas nações. Em muitos países, direitos básicos como direitos políticos e liberdade de expressão são suprimidos com a justificativa de que para haver progresso devem haver sacrifícios. No Brasil, o cerceamento de diversas liberdades instrumentais dificulta a efetividade das políticas públicas de desenvolvimento econômico. A exemplo, citamos empreendedores de pequeno porte que ao vislumbrarem uma oportunidade de negócio depositam suas esperanças e abraçam tal oportunidade, todavia acabam presos e sufocados por diversos tipos de barreiras: informacionais, financeiras, procedimentais e etc. Em suma, acabam por dispensar a oportunidade ou por serem demasiadamente onerados em um amplo aspecto quando a enfrentam, encontrando o sucesso tardio, ou na pior das hipóteses, o fracasso.

Atualmente, estudiosos e economistas elaboram inúmeras teorias que possuem como objetivo explicar o fracasso econômico de diversos países do globo. Algumas teorias justificam o fracasso econômico dessas nações com a premissa de que a localização geográfica não favorece ao desenvolvimento. Outras teorias apontam que o fator cultural da nação pode ser prejudicial ao seu desenvolvimento econômico. Uma terceira abordagem, alega que o fracasso econômico está ligado à ingerência dos governantes.

Este trabalho pretende demonstrar que o fracasso econômico é consequência do cerceamento de liberdades. Seguindo como referencial teórico a teoria de Amartya Sen e o que ela se propõe, nossa abordagem será em favor de demonstrar que o sucesso econômico está relacionado diretamente com fatores democráticos, e que o avanço econômico está vinculado às diversas liberdades as quais a democracia se propõe.

A política pública é a forma pela qual o Estado intervém nas relações sociais para solucionar problemas ${ }^{1}$. Pelo reconhecimento de sua importância, estudos sobre a intervenção estatal na garantia do desenvolvimento e do combate à desigualdade

\footnotetext{
1 Secchi (2017, p. 2) aponta dois elementos fundamentais de uma política pública. O primeiro elemento é a intencionalidade e o segundo elemento a resposta a um problema público. Assim, a razão de seu estabelecimento é a necessidade de solução de determinado problema coletivamente relevante.
} 
foram fomentados. O centro das preocupações passou a ser o planejamento da política pública uma vez que o bom andamento desta garante desenvolvimento, além do mais, gastos públicos são dedicados para a sua execução. A investigação sobre o surgimento do estado de bem-estar social é desenvolvida sob uma metodologia de análise bibliográfica, demonstrando que apesar das divergências quanto ao marco inicial, suas estruturas fundamentam direitos e as políticas públicas são parte integrante de todo o processo. Iniciaremos essa abordagem falando das liberdades que permeiam um estado democrático com foco na saúde e educação no Brasil, realizando um paralelo com as respectivas situações antes e após da Constituição de 1988. Em seguida, trataremos do surgimento do estado de bem-estar social e a importância das políticas públicas.

\section{UMA PERSPECTIVA DE DESENVOLVIMENTO}

Inicialmente, Amartya Sen apresenta duas razões pelas quais a liberdade é central para o processo de desenvolvimento (SEN, 2010, p. 17). São elas:

1) A razão avaliatória: a avaliação do progresso tem de ser feita verificando-se primordialmente se houve aumento das liberdades das pessoas.

2) A razão da eficácia: a realização do desenvolvimento depende inteiramente da livre condição de agente das pessoas. (SEN, 2010, p. 17).

Os valores sociais e os costumes como a igualdade entre os sexos, a qualidade da educação, o tamanho da família e os padrões de qualidade nas quais essas vivem, o tratamento do meio ambiente, dentre tantos outros fatores sociais, contribuem para o surgimento de elementos que podem abalar a confiança nas instituições democráticas. É preciso ressaltar que a prosperidade de uma nação, apesar de sofrer influências de vários fatores, tem na liberdade seu pilar fundamental (SEN, 2010, p. 23). As liberdades interagem umas com as outras e o desenvolvimento econômico não é estranho a isso, seja promovendo segurança seja facilitando o acesso ao mercado econômico.

Como liberdades entendemos ser todas aquelas que permeiam um estado democrático de direito, liberdade política, liberdade de expressão, liberdade 
religiosa, liberdade de locomoção, e dentre tantas outras, não menos importante, a liberdade econômica (SEN, 2010, p. 23).

Segundo Sen (2010), o conceito de pobreza não está relacionado apenas com o baixo nível de renda, sendo a renda, um fator agravante para o status de miséria (SEN, 2010, p. 120-121). O autor relaciona pobreza como privação de capacidades e expõe os seguintes argumentos para expor seu entendimento:

1) A pobreza pode sensatamente ser identificada em termos de privação de capacidades; a abordagem concentra-se em privações que são intrinsecamente importantes (em contraste com a renda baixa, que é importante apenas instrumentalmente).

2) Existem outras influências sobre a privação de capacidades - e, portanto, sobre a pobreza real - além do baixo nível de renda (a renda não é o único instrumento de geração de capacidades).

3) A relação instrumental entre baixa renda e baixa capacidade instrumental é variável entre comunidades e até mesmo entre famílias e indivíduos (o impacto da renda sobre as capacidades é contingente e condicional). (SEN, 2010, p. 120-121).

Assim, concluímos que existe uma diferença entre pobreza como privação de liberdades e pobreza de renda e elas se relacionam, comunicam e interagem, sendo que o combate à primeira consequentemente acarretaria o combate à segunda.

Expõe Sen (2010):

Esta última relação pode ser particularmente importante para a eliminação da pobreza de renda. Não ocorre apenas que, digamos, melhor educação básica e serviços de saúde elevem diretamente a qualidade de vida; esses dois fatores também aumentam o potencial de a pessoa auferir renda e assim livrar-se da pobreza medida pela renda. quanto mais inclusivo for o alcance da educação básica e dos serviços de saúde, maior será a probabilidade de que mesmo os potencialmente pobres tenham uma chance maior de superar a penúria (SEN, 2010, p. 124).

Ainda sobre o terceiro argumento, este é "particularmente importante quando se examina e avalia a ação pública destinada a reduzir a desigualdade e a pobreza" (SEN, 2010, p. 121).

Daron Acemoglu e Robinson (2012) apresentam uma nova perspectiva fundada na propriedade privada e na livre iniciativa. Para os autores, existem nações extrativistas, sendo estas aquelas que exploram a grande massa populacional usando o argumento de unidade. Em seu livro "Por Que As Nações Fracassam?", no qual é coautor juntamente com James Robinson, Acemoglu expõe 
diversos exemplos de economias que a princípio eram extrativistas e ao mudarem suas políticas de desenvolvimento econômico se tornaram nações inclusivas. Por nações inclusiva, entendem os autores serem aquelas nas quais são criadas políticas públicas de desenvolvimento econômico, ou seja, que facilitam e favoreçam o acesso ao mercado daqueles que possuem espírito empreendedor (ACEMOGLU; ROBINSON, 2012. p. 78-84).

Tratando-se de livre iniciativa, Amartya Sen se posiciona afirmando que a estrutura econômica tradicional impõe barreiras que dificultam o acesso de pequenos empreendedores e pequenos agricultores aos grandes mercados de troca. O autor ainda ressalta a importância de vislumbrarmos o papel do mercado como fator de suma importância para o crescimento de uma nação (SEN, 2010, p.20).

A distinção entre as visões estreita e ampla da oportunidade será bastante central quando passarmos da ideia básica de liberdade a conceitos mais específicos, como as capacidades que uma pessoa tem. Devemos examinar, nesse contexto, se a capacidade de uma pessoa para levar o tipo de vida que valoriza deve ser avaliada apenas pela alternativa de culminação com o qual ela realmente acabaria, ou através do uso de uma abordagem mais ampla, que leve em conta o processo de escolha envolvido, em especial as alternativas que ela também poderia escolher, dentro de sua aptidão real para fazê-lo (SEN, 2011, p.110).

Sem prejuízo de demais perspectivas econômicas, a Constituição do Brasil de 1988 traz no artigo $1^{\circ}$ os princípios fundamentais da República (BRASIL, [2016]):

\footnotetext{
Art. $1^{\circ} \mathrm{A}$ República Federativa do Brasil, formada pela união indissolúvel dos Estados e Municípios e do Distrito Federal, constitui-se em Estado Democrático de Direito e tem como fundamentos:

I- a soberania;

II- a cidadania

III- a dignidade da pessoa humana;

IV- os valores sociais do trabalho e da livre iniciativa;

V- o pluralismo político. (BRASIL, [2016]).
}

No Brasil, vivemos o paradigma de um estado democrático de direito, fazendo de nossa Constituição um expoente democrático. Assim, no que tange a direitos econômicos, identificamos um rol de princípios que norteiam a ordem econômica brasileira, dentre eles, a livre concorrência e a propriedade privada bem como a redução das desigualdades regionais e sociais. Não obstante ao estado democrático em que vivemos, atravessamos uma situação de grave crise econômica, 
em que o discurso de cerceamento de direitos é crescente em face do desenvolvimento econômico. A partir disso, seguem informações da variação do PIB brasileiro nos últimos anos:

Gráfico 1 - Taxa Anual de crescimento do PIB brasileiro

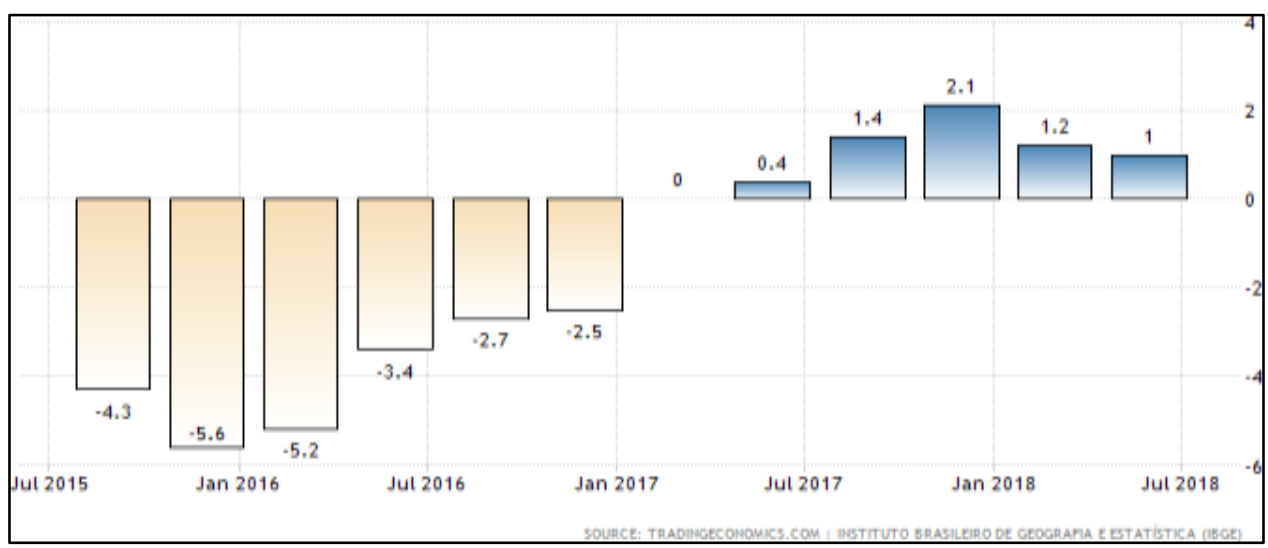

Fonte: Trading Economics (c2020).

O gráfico 1 refere-se ao PIB brasileiro, tomando como marco referencial o mês de julho de 2015, sendo que a contar deste marco até janeiro de 2017 é observada uma queda das riquezas internas do país. A superação se dá a partir de julho de 2018 e parece manter um discreto crescimento.

\section{Mapa 1 - Rendimento médio mensal domiciliar}



Fonte: IBGE (c2020a).

Na mesma linha, os dados do IBGE coletados no ano de 2013, conforme o mapa 1, demonstram os níveis de rendimento mensal organizados por Estados no 
Brasil. Estados com menor rendimento médio mensal domiciliar e também os índices de alfabetização, respectivamente. Nos Estados do Norte e Nordeste é possível observar simultaneamente uma baixa renda mensal e um alto índice de analfabetismo (mapa 2).

\section{Mapa 2 - Índice de alfabetização no Brasil.}

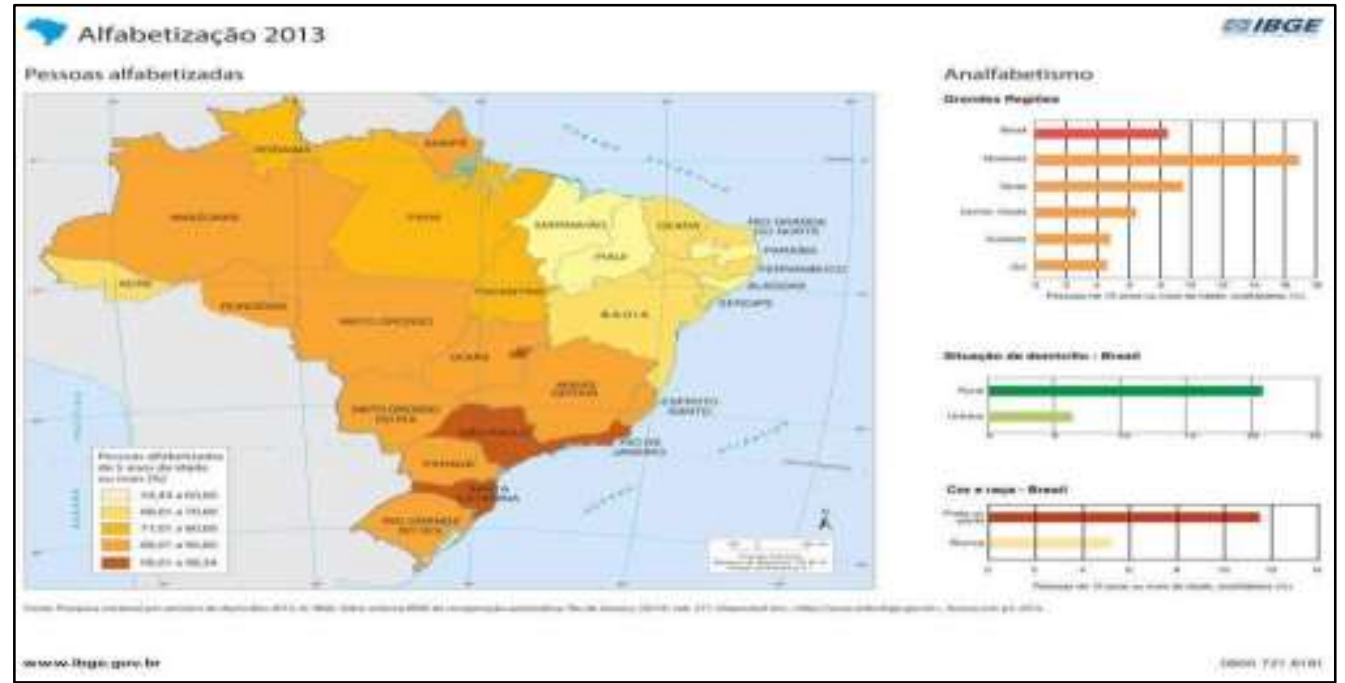

Fonte: IBGE (c2020b).

Uma multiplicidade de fatores afeta a trajetória da desigualdade. Essas variáveis mudam de acordo com cada nação. No Brasil, fatores como baixa fertilidade das mulheres, consequentemente elevada oferta de mão de obra de jovens com baixa escolaridade até os anos 70 foi um fator contributivo para o aumento da desigualdade. Essa massa de indivíduos, ao ingressarem no mercado de trabalho passaram a ter renda e mesmo as mulheres, com renda significativamente menor que as renda dos homens, contribuíram para a queda no índice de desigualdade no Brasil. A expressiva taxa de redução da desigualdade nos anos de 1985 a 2015, momento econômico vivido sob a égide do regime democrático, é explicada pelo mecanismo de inclusão dos outsiders² ${ }^{2}$ O mecanismo de inclusão dos outsiders se dividiu em duas fases distintas (ARRETCHE, 2018, p.3).

\footnotetext{
${ }^{2}$ A inclusão dos outsiders, segundo Arretche, deriva de uma mudança paradigmática nos pilares do modelo conservador de política social adotado no país desde Getúlio Vargas. Incorporou a titularidade de direitos de aposentadoria, saúde e educação. O regime conservador de política social adotado desde os anos 30 produziu uma divisão entre outsiders e insiders. Apenas os inseridos no mercado formal de trabalho eram protegidos por leis trabalhistas, isso levando em conta o contexto de tamanho reduzido do setor industrial e altas taxas de desemprego. $O$ vínculo trabalhista era requisito para aposentadorias e serviços de saúde (ARRETCHE, 2018, p. 3).
} 
Esclarece a autora:

O mecanismo de inclusão dos outsiders se desdobrou em duas fases distintas. A primeira resulta da conjuntura crítica da transição para a democracia. Dela emerge o capítulo social da CF de 1988, que vinculou aposentadorias não contributivas ao valor do salário mínimo, bem como constitucionalizou os sistemas universais e gratuitos de saúde e educação. A segunda fase é resultado de mudanças endógenas associadas à criação de categorias de beneficiários dessas políticas (policies). As elevadas taxas de participação eleitoral dos mais pobres, combinadas à constitucionalização dos direitos sociais converteram esses beneficiários, situados no piso e no meio da escala contínua da distribuição da renda, em eleitores interessados na expansão das políticas que os favoreçam. Dado seu tamanho numérico, esses eleitores são decisivos para uma eleição majoritária. Partidos conservadores e de esquerda tendem a convergir para atender às suas demandas. A competição política por essa categoria de eleitores contribui, por sua vez, para sua contínua expansão (ARRETCHE, 2018, p. 3).

No Brasil, em 2009, o coeficiente de $\mathrm{Gini}^{3}$ da renda caía de 0,565, considerando impostos e transferências, para 0,479, incluindo gasto social em saúde e educação. A listagem de fatores a serem considerados na mensuração de desigualdade varia entre os autores. Partindo dessa premissa, a autora fez menção a duas determinantes. Dimensões não monetárias cuja trajetória "pode ser empiricamente observada e é diretamente afetada por regras de acesso aos serviços públicos" (ARRETCHE, 2018, p.4).

As políticas de transferência de renda, saúde e educação estão no núcleo das dimensões redistributivas. Políticas sociais produzem estratificação uma vez que regulamentam o mercado de trabalho, serviços públicos de saúde e educação, na medida em que a regulamentação desses direitos é condicionada à renda ou à condição de ocupação. Alguns indivíduos acumularão vantagens e outros desvantagens (ARRETCHE, 2018, p. 6).

\section{A EDUCAÇÃO NO BRASIL}

A educação no Brasil é notoriamente inacessível. Nos anos 1980, cerca de $85 \%$ dos jovens com menos de 16 anos de idade havia se matriculado na escola e

\footnotetext{
${ }^{3}$ O coeficiente de Gini, criado pelo matemático italiano Conrado Gini, é um instrumento para medir o grau de concentração de renda em determinado grupo. Esse índice aponta a diferença entre os rendimentos dos mais pobres e dos mais ricos. Suas variáveis são de zero, que é uma situação de igualdade, involuíndo até um.
} 
menos da metade completou 4 anos de estudo (ARRETCHE, 2018, p. 6). No final da década de 1980, com o advento da Constituição, o resultado dos índices da educação no país apresentava mudanças. Dados de frequência escolar da população de 0 a 6 anos era de 15,3\% e o da população de 15 a 19, no ensino médio, era de $16,5 \%$. A taxa de analfabetismo da população de 15 anos e mais, por sua vez, estava em 18,8\% em 1989 (BRASIL, 2014a, p. 9).

De acordo com gráfico 2, a seguir apresentado, no ano de 200,1 o índice de alfabetização no Brasil era de 87,6\%. Em 2011, teve o índice de maior expressividade, $91,4 \%$. No ano seguinte, constatou-se um pequeno aumento de 0,1\% no índice de analfabetização (BRASIL, 2014a, p. 15).

Gráfico 2 - Taxa de alfabetização da população de 15 anos e mais

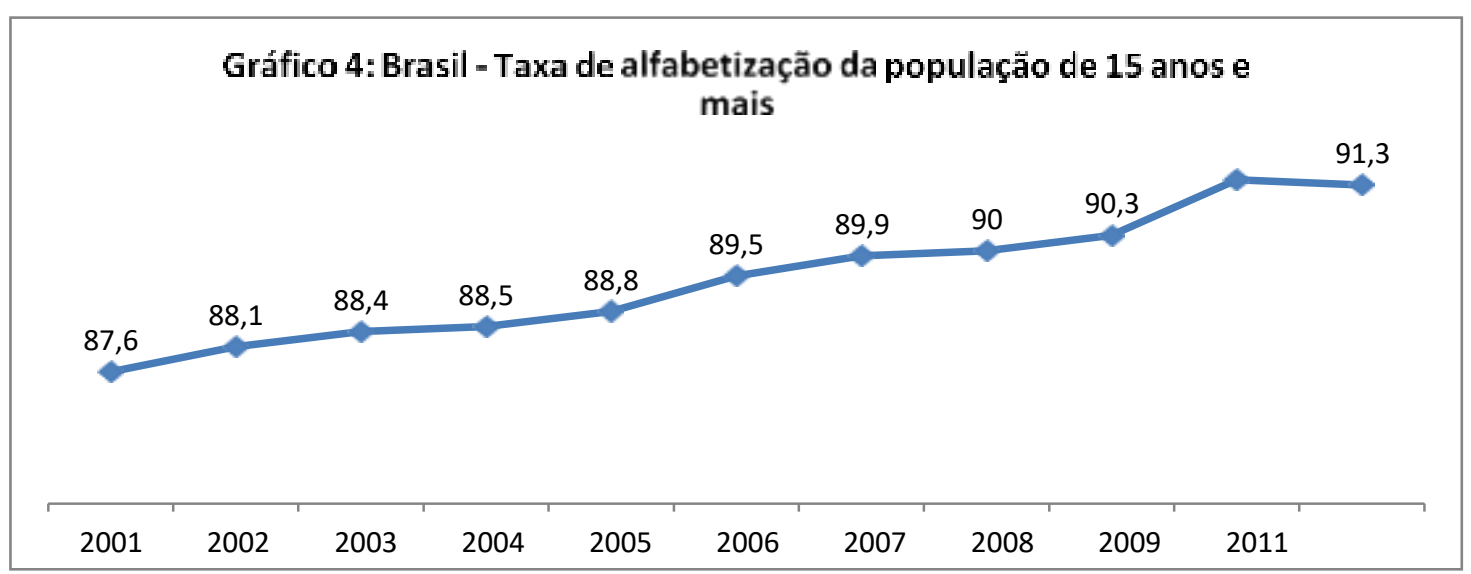

Fonte: Microdados da Pnad (IBGE) citado por Brasil (2014a, p. 15).

O artigo 212, da Constituição do Brasil de 1988, estabelece que:

Art. 212. A União aplicará, anualmente, nunca menos de dezoito, e os Estados, o Distrito Federal e os Municípios vinte e cinco por cento, no mínimo, da receita resultante de impostos, compreendida a proveniente de transferências, na manutenção e desenvolvimento do ensino. (BRASIL, [2016]).

Diante da máxima constitucional bem como de outros artigos que atribuíram importância ao ensino de qualidade, as políticas públicas passaram a ser desenvolvidas. Em 1993, o congresso nacional aprovou um Compromisso Nacional de Educação Para Todos e um Plano Nacional de Educação Para Todos. No ano seguinte, realizou a Conferência Nacional de Educação Para Todos. Em 1996, dois grandes dispositivos legais foram aprovados, sendo eles a Lei de Diretrizes e 
Bases da Educação Nacional e o segundo foi o Fundo de Manutenção e Desenvolvimento do Ensino Fundamental e de Valorização do Magistério (BRASIL, 2014a, p. 9). Dentre esses e outras investimentos estatais, na forma de políticas públicas, buscou promover o incentivo na educação básica. Mudanças são notadas.

Gráfico 3 - Taxa de frequência à escola - população de 0 a 5 anos 2001 - 2012

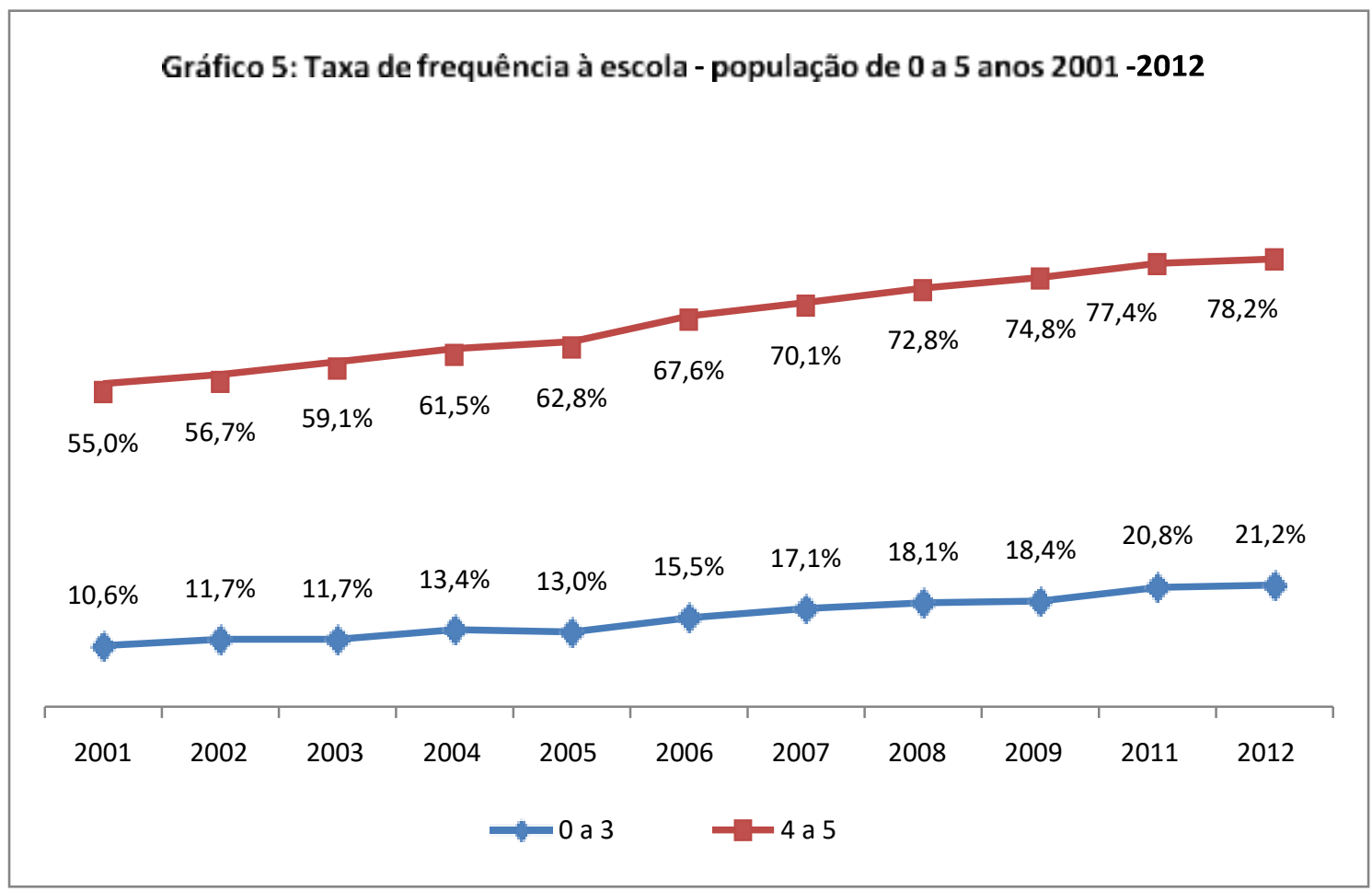

Fonte: Elaborado pelo INEP com dados do IBGE/Pnad citado por Brasil (2014a, p. 12).

Gráfico 4 - Taxa de frequência à escola - população de 6 a 14 anos 2001 - 2012

Gráfico 6: Taxa de frequência à escola - população de 6 a 14 anos 2001 -2012



Fonte: Elaborado pelo INEP com dados do IBGE/Pnad citado por Brasil (2014a, p. 12). 
No ano de 2001 (gráfico 3), o índice de frequência escolar para crianças de 0 a 3 anos saltou de 10,6\% para 21,2\% no ano de 2012. Crianças de 4 a 5 anos, houve um aumento na frequência de 55,0\% no ano de 2001 para 78,2\% no ano de 2012.

No gráfico 4, a taxa de frequência da população de 6 a 14 anos varia entre $95,3 \%$ no ano de 2001 a 98,2\% no ano de 2012. Em um contexto de aumento no acesso às liberdades instrumentais (SEN, 2010. p.25), proporcionado pelo advento da Constituição do Brasil de 1988, dados apontam expressivas mudanças, reforçando o papel do Estado na promoção de políticas públicas em acordo com os objetivos do Estado brasileiro, elencados no artigo $3^{\circ}$ da Constituição de 1988 (BRASIL, [2016]).

\section{A SAÚDE NO BRASIL}

O sistema de saúde, no Brasil, também sofreu mudanças advindas da Constituição do Brasil de 1988. A Constituição de 1988 criou o Sistema Único de Saúde proporcionando acesso universal e gratuito e substituiu o modelo de seguro vigente até então (BRASIL, [2016]). Nos anos 1980, os trabalhadores formais eram cerca de $40 \%$. Os $60 \%$ restantes da população não assegurados e contribuíam para o financiamento do sistema vigente naquela época uma vez que o custeio era transferido para o preço dos produtos consumidos no país (ARRETCHE, 2018. p. 12). A Constituição do Brasil de 1988 estabelece no artigo 196 que a saúde é direito de todos e dever do estado, garantido mediante políticas sociais e econômicas que visem à redução do risco de doença e de outros agravos e ao acesso universal e igualitário às ações e serviços para sua promoção, proteção e recuperação. (BRASIL, [2016]).

A ausência de direitos como saúde e saneamento básico traz, por consequências, algumas doenças, dentre elas, a esquistossomose, hanseníase, leishmaniose, leptospirose, malária e tracoma. Essas doenças, por serem típicas de países pobres, estabelecem um importante informativo de desigualdade e exclusão social. A influência humana no meio ambiente, a expansão das atividades econômicas e fatores individuais como aumento da suscetibilidade imunológica 
causada por ausência de recursos alimentares. Estima-se que a malária cause 500 milhões de infecções e mais de 1 milhão de mortes em todo mundo no período anual, 1 bilhão de pessoas infectadas pela tuberculose nos próximos 20 anos e aproximadamente 35 milhões de vidas ceifadas. Doenças relacionadas a pobreza matam 6 milhões de pessoas por ano (BRASIL, 2014b, p. 258).

O gráfico 5 traz algumas informações sobre o cenário nacional de doenças relacionadas a pobreza. Os indicativos são de 2008 a 2013. Nesse período, ocorreram 196.150 internações no Brasil. Em 2011, 36.087 infecções foram registradas, sendo o período de maior representatividade de todo o período analisado. A tabela 1 informa o número de internações de cada Estado da federação (BRASIL, 2014b, p. 260).

Gráfico 5 - Sistema de Informação Hospitalares/ SUS (SIH/SUS).

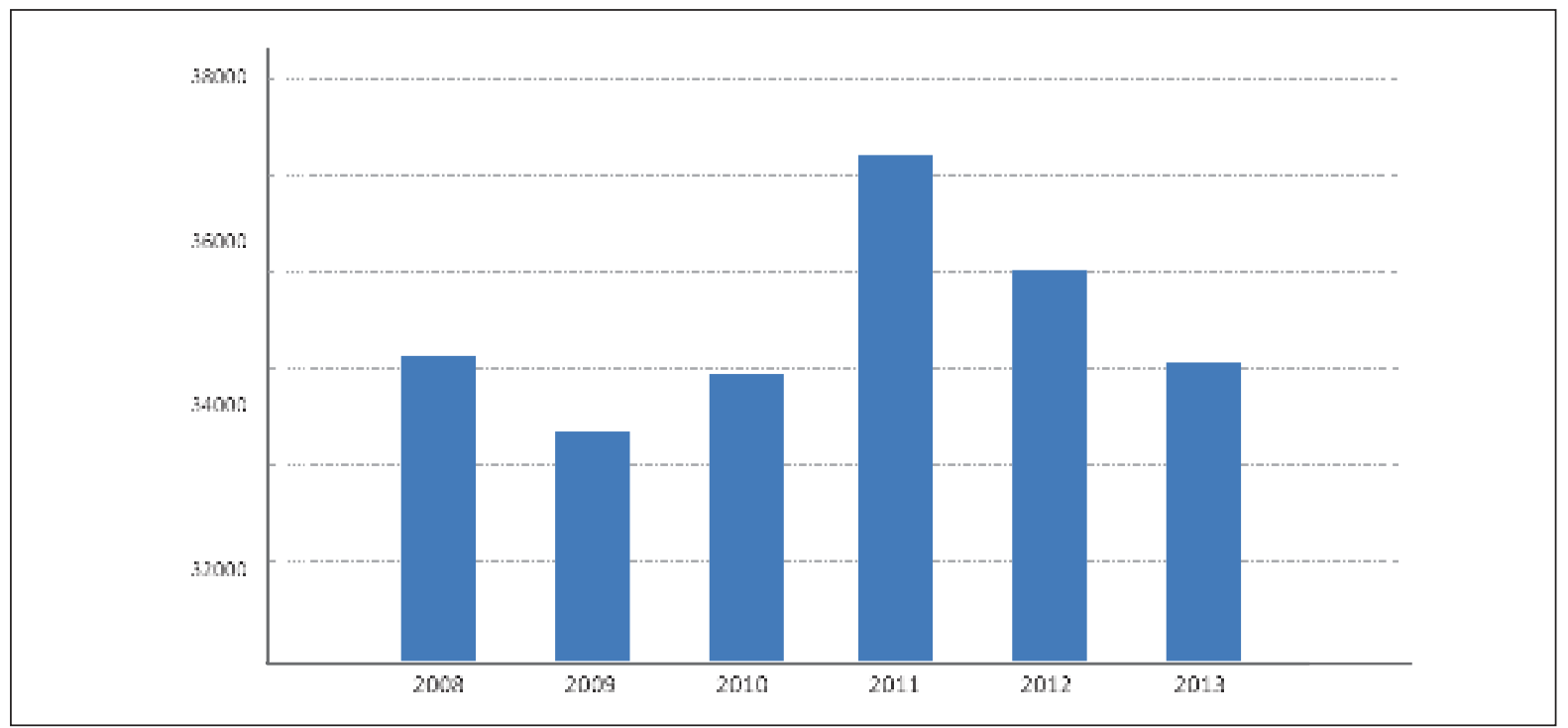

Fonte: Sistema de Informações Hospitalares/SUS (SIH/SUS) citado por Brasil (2014b, p. 260).

Tabela 1 - Sistema de Informação Hospitalares/ SUS (SIH/SUS)

$\begin{array}{lccccccl}\text { UF } & 2008 & 2009 & 2010 & 2011 & 2012 & 2013 & \text { Total } \\ \text { Sergipe } & 144 & 154 & 197 & 207 & 155 & 118 & 975 \\ \text { Amapá } & 287 & 357 & 280 & 381 & 350 & 258 & 1.913 \\ \text { Distrito Federal } & 368 & 333 & 322 & 321 & 307 & 320 & 1.971 \\ \text { Roraima } & 353 & 428 & 574 & 424 & 337 & 358 & 2.474 \\ \text { Mato Grosso } & 420 & 418 & 409 & 461 & 414 & 491 & 2.613 \\ \text { Espírito Santo } & 317 & 425 & 324 & 500 & 467 & 644 & 2.677 \\ \text { Alagoas } & 266 & 361 & 368 & 554 & 615 & 562 & 2.726 \\ \text { Rio Grande do Norte } & 501 & 623 & 614 & 618 & 595 & 494 & 3.445\end{array}$




$\begin{array}{lccccccc}\text { Piauí } & 713 & 643 & 625 & 532 & 504 & 561 & 3.578 \\ \text { Mato Grosso do Sul } & 693 & 663 & 680 & 555 & 557 & 591 & 3.739 \\ \text { Tocantins } & 887 & 684 & 573 & 605 & 599 & 463 & 3.811 \\ \text { Acre } & 785 & 932 & 908 & 538 & 481 & 461 & 4.105 \\ \text { Goiás } & 1.435 & 602 & 714 & 700 & 597 & 1.023 & 5.071 \\ \text { Maranhão } & 990 & 871 & 703 & 812 & 677 & 1.073 & 5.126 \\ \text { Paraíba } & 559 & 675 & 889 & 971 & 1.001 & 1.034 & 5.129 \\ \text { Amazonas } & 1.167 & 992 & 1.059 & 1.020 & 834 & 754 & 5.826 \\ \text { Rondônia } & 900 & 1.236 & 1.288 & 1.244 & 975 & 801 & 6.444 \\ \text { Santa Catarina } & 1.292 & 1.238 & 1.151 & 1.434 & 1.231 & 1.164 & 7.510 \\ \text { Ceará } & 1.204 & 1.668 & 1.351 & 1.399 & 1.135 & 1.190 & 7.947 \\ \text { Paraná } & 2.295 & 1.194 & 1.254 & 1.338 & 1.347 & 1.299 & 8.727 \\ \text { Bahia } & 1.642 & 1.780 & 2.058 & 2.066 & 1.819 & 1.712 & 11.077 \\ \text { Pará } & 1.742 & 2.283 & 2.607 & 2.976 & 1.567 & 1.107 & 12.282 \\ \text { Minas Gerais } & 2.179 & 2.176 & 2.083 & 2.335 & 2.093 & 1.994 & 12.860 \\ \text { Rio Grande do Sul } & 2.311 & 2.033 & 2.318 & 2.376 & 2.187 & 1.994 & 13.219 \\ \text { Pernambuco } & 2.220 & 2.055 & 2.305 & 2.603 & 2.951 & 2.671 & 14.805 \\ \text { Rio de Janeiro } & 2.473 & 2.483 & 2.594 & 3.001 & 2.726 & 2.486 & 15.763 \\ \text { São Paulo } & 3.924 & 3.254 & 3.527 & 6.116 & 7.264 & 6.252 & 30.337 \\ \text { Brasil } & 32.067 & 30.561 & 31.775 & 36.087 & 33.785 & 31.875 & 196.150\end{array}$

Fonte: Sistema de Informações Hospitalares/SUS (SIH/SUS) citado por Brasil (2014b, p. 262).

Para o cálculo da taxa de internação hospitalar, foram consideradas as hospitalizações para as doenças de interesse por UF de residência. A mediana nacional foi de 1,7 por 10 mil habitantes, com variação de 0,53 a 7,31. As maiores taxas estiveram concentradas na Região Norte, especialmente em Roraima 7,3 internações, Acre 5,7 internações, Rondônia 4,6 internações, Amapá 3,4 internações e Tocantins 3,0 internações (BRASIL, 2014b, p. 264).

Este trabalho teve por objetivo analisar o desenvolvimento brasileiro sob uma perspectiva de liberdades. O desenvolvimento econômico não está restrito apenas ao desenvolvimento do mercado. Obviamente o desenvolvimento deste é de suma importância para o desenvolvimento da sociedade brasileira. A premissa de que o mercado se basta, muita das vezes tomada de assalto por agentes públicos e estudantes de economia, não se sustenta frente à realidade de uma nação que enfrenta típicos problemas de países que lutam para combater a pobreza. O desenvolvimento econômico é pautado em liberdades a que a Constituição de 1988 se propõe, fundamentada no espírito combativo de desigualdades, traça sentido rumo ao desenvolvimento igualitário. Por fim, este trabalho fará breves considerações a respeito de políticas públicas, uma vez que essas são o instrumento de combate às desigualdades. 


\section{O SURGIMENTO DO ESTADO DE BEM-ESTAR SOCIAL}

As políticas públicas são uma forma de agir estatal, dentro de um paradigma de estado de bem-estar social. Com larga expansão no século XX, apesar de haver provisão de serviços sociais no século passado em alguns países como a Alemanha, na criação de programas de proteção a idosos e mulheres bem como sistemas assistenciais para incapacitados, o fenômeno do estado provedor institucionalizou-se. A partir de então, surgem programas de proteção social assegurando direitos em várias áreas como seguridade social, saúde, educação e habitação (ARRETCHE, 1995). Muitas teorias se propõem a explicar o surgimento do estado de bem-estar social e o seu desenvolvimento. As correntes que consideram o surgimento e a expansão do estado de bem-estar social com peso em causações de natureza econômica, tem esse modelo proveniente de profundas transformações desencadeadas a partir do século XIX, tais como a industrialização e modernização das sociedades. Para eles, esse modo de produção desencadeou problemas, que por sua vez, tiveram como contramedida a criação de padrões mínimos com a finalidade de garantir a existência digna (ARRETCHE, 1995).

[...] os problemas sociais com os quais os serviços sociais têm de lidar são resultado das mudanças sociais sobretudo, demográficas) desencadeadas pela industrialização. A consolidação da fábrica como núcleo central da atividade produtiva implica uma transformação radical das sociedades, transformação esta que determina o surgimento de novos mecanismos de garantia da coesão e integração sociais. Nada melhor do que uma citação dos próprios autores para que fique claro o papel central e determinante desempenhado pelo desenvolvimento industrial no surgimento dos programas sociais (ARRETCHE, 1995, p. 6).

Uma segunda corrente adota o posicionamento de que o estado de bemestar social surgiu com o advento do modo capitalista de produção, seja para suprimir suas necessidades de acumulação seja para legitimar o próprio sistema. Para essa corrente, todas as despesas estatais, seja qual estiver atrelada a função que o estado desempenha seja para garantir os diretamente acumulação ou para corrigir os efeitos sociais da acumulação via capital social ou via despesas sociais (ARRETCHE, 1995). 
A origem dos programas sociais é explicada, portanto, como uma resposta funcional à necessidade de constituição da classe operária, condição essencial para o desenvolvimento do capitalismo. Esta função (de socialização da classe operária no capitalismo) só pode ser cumprida por um poder estatal, pois o processo de integração daquela classe supõe a existência de uma associação política de dominação: o poder estatal. Por outro lado, a dinâmica de desenvolvimento das políticas sociais diz respeito a um processo, interno à esfera estatal, de compatibilização de duas exigências contraditórias: as exigências da classe trabalhadora e as necessidades da acumulação de capital. Na verdade, a esfera estatal reage a estas duas ordens de pressões, levando em conta os pré-requisitos de uma economia do trabalho e as possibilidades orçamentárias (ARRETCHE, 1995, p. 18).

Uma terceira corrente, demonstrada por Arretche (1995), acredita que o estado de bem-estar social é resultado de uma ampliação progressiva de direitos civis, políticos e sociais. Para os autores que se filiam a esse posicionamento, a cidadania ${ }^{4}$ é explicada pela ampliação e evolução de direitos, bem como pela maior acessibilidade a esses direitos antes não acessíveis por determinadas camadas sociais (ARRETCHE, 1995). Outro fator que propiciou uma expansão ao estado de bem-estar social foram as guerras. Nesse sentido afirma a autora:

A experiência da guerra é particularmente significativa nesta direção. Ao fim de cada guerra, parece ter ocorrido um ato de refundação social e, portanto, de reafirmação cada vez mais acentuada da natureza do Estado protetor/Estado de Bem-Estar. Tratava-se de renovar os laços sociais que constituem a nação e, portanto, de dar vazão ao movimento de democratização das relações sociais através do Estado, movimento este que vai dos direitos civis aos direitos sociais, passando pelos direitos políticos. (ARRETCHE, 1995, p. 21).

Para aqueles que entendem que o estado de bem-estar social surgiu do resultado do acordo entre capital e trabalho organizado, dentro de um sistema capitalista, consideram o modelo um fenômeno que surgiu como resposta ao próprio capitalismo. O processo capitalista gera necessidades ou requerimentos para a política social (ARRETCHE, 1995, p. 40).

[...] ainda que o aparato estatal seja relativamente autônomo nas sociedades capitalistas, ele deve agir para responder aos imperativos do

\footnotetext{
${ }^{4} \mathrm{O}$ conceito de cidadania tem início no século XVII e compreende três tipos de direitos. Os direitos civis estão relacionados à liberdade individual, os direitos políticos estão relacionados ao exercício do poder político e os direitos sociais estão relacionados a participação do indivíduo na produção de riqueza da sociedade.
} 
processo de acumulação de capital. Seja porque os funcionários do Estado são de origem burguesa e, portanto, partilham da ideologia da classe dominante; seja porque a burguesia tem recursos econômicos para exercer pressão política; seja ainda porque ignorar a acumulação de capital pode implicar a evasão de capitais das economias nacionais e, portanto, minar as bases fiscais do Estado-nação; enfim, fundamentalmente, a economia capitalista tem uma racionalidade à qual o Estado deve submeter-se. (ARRETCHE, 1995, p. 23).

Uma outra corrente teórica entende que o estado de bem-estar social não possui um marco estático de sua criação, é fruto de uma construção histórica e social. Países capitalistas com o mesmo grau de desenvolvimento possuem modelos diferentes de políticas sociais, sendo essas das mais variadas formas. Para eles, a mobilização da classe trabalhadora no interior da matriz de poder resultou em modelos diversos de estado de bem-estar social (ARRETCHE, 1995). O marco regulatório usado para a compreensão da medida do poder é delimitado pelos recursos de poder que a classe trabalhadora possui. O poder, por sua vez, é medido pelo grau de organização sindical e pela força dos partidos de esquerda (ARRETCHE, 1995).

Uma última corrente entende que o estado de bem-estar social é o resultado de configurações históricas particulares de estruturas estatais e instituições políticas. Para eles, o modelo de estado não surgiu como consequência apenas de fatores internos do próprio estado de maneira estrita. Consideram que fatores exógenos ao estado também contribuíram para o surgimento do estado de bem-estar social (ARRETCHE, 1995).

\section{AS FASES DAS POLÍTICAS PÚBLICAS E SUA IMPORTÂNCIA}

O estado de bem-estar social é caracterizado pela intervenção do estado na sociedade, seja garantindo direito seja regulando. $O$ estudo das políticas públicas didaticamente a divide em fases. As fases das políticas públicas não é algo muito bem definido e parte dos estudiosos de políticas públicas e suas estruturas. Segundo Secchi, autor este que foi usado como referencial para a divisão das etapas das políticas públicas, as mesmas se dividem em identificação do problema, formação da agenda, formulação de alternativas, tomada de decisões, implementação, avaliação e extinção (SECCHI, 2017, p.47). A seguir faremos uma breve abordagem da 
conceituação de problema público e as decisões que permeiam as fases das políticas públicas.

Em análise das tomadas de decisão, tentamos entender as estruturas que as fundamentam. Em primeiro lugar, para que as tomadas de decisão sejam compreendidas, deve-se compreender o conceito de poder. Ham e Hill (1993, p. 9498) traz que para o grupo dos teóricos pluralistas o poder está concentrado nas mãos de uma elite. Essa concepção vem sendo superada uma vez que a crítica aponta que diversas questões não chegam a entrar em pauta de tomada de decisão pois são excluídas de forma indireta por atores externos a aqueles que diretamente tomam decisões. Nesses casos, há ocorrência de um conflito velado.

\begin{abstract}
A análise do manuseio de três questões políticas chave nos anos cinquenta desenvolvimento urbano, educação pública e escolha de candidatos a cargos políticos - revelou uma situação em que o poder não estava concentrado nas mãos de um único grupo, como os teóricos elitistas haviam suposto. Pelo contrário, devido a que os recursos que contribuíam para o poder estavam consideravelmente bem distribuídos por toda a população, dever se - ia concluir que o poder estava fragmentado entre diferentes atores. E, embora apenas umas poucas pessoas tivessem influência direta sobre decisõeschave, a maioria tinha influência indireta mediante o poder do voto (HAM; HILL, 1993, p. 94).
\end{abstract}

A análise de poder deve ser feita juntamente com a relação entre poder e interesses. Para os pluralistas, baseados numa concepção liberal, os interesses e preferências são iguais entre as pessoas. São "aquilo que elas afirmam ser e que a natureza destes interesses pode ser inferida através da ação ou da inação política" (HAM; HILL, 1993, p. 101).

O desenvolvimento econômico igual e sustentável está diretamente ligado as liberdades que permeiam o próprio processo de desenvolvimento. Essas liberdades estão diretamente vinculadas ao processo democrático. Em se tratando de democracia, não estamos referindo apenas ao voto direto, mas sim, a uma gama de direitos de inclusão e acessibilidade. Diversos atores estão envolvidos no desenvolvimento socioeconômico de uma determinada área. Os agentes não governamentais desempenham grande papel no cumprimento da estratégia. Nesse aspecto, Secchi divide os atores em dois grupos: atores governamentais, formados por agentes políticos, designados politicamente, burocratas e juízes. Atores não governamentais, formados por grupos de interesse, partidos políticos, meios de 
comunicação, think tanks, destinatários das políticas públicas, organização do terceiro setor, outros stakeholders, tais como fornecedores, organismos internacionais, comunidades epistêmicas, financiadoras, especialistas, etc (SECCHI, 2017, p.100-101).

Cada arena política tem uma configuração de atores bastante peculiar, com prevalência de alguns e ausência de outros. A arena política da área da saúde é ocupada por atores diferentes da arena de segurança pública, que por sua vez em configuração diferente da arena de reformas administrativas. A presença dos atores em uma arena acontece em função de quão diretos são os resultados da política pública sobre suas atividades, a probabilidade de efeitos positivos e negativos da política pública sobre suas atividades, bem como a acessibilidade aos processos decisórios e/ou de implementação das políticas públicas (SECCHI, 2017, p. 101).

A importância do amplo acesso aos direitos fundamentais não exclui o direito de troca e transacionar. Pelo contrário, esses direitos são sacramentados na forma de princípios fundamentais elencados no artigo $1^{0}$ da Constituição da República Federativa do Brasil de 1988. O paradigma de um estado democrático de direito é a premissa estruturante de direitos, não é possível falar em amplitude de direitos e garantias em um estado totalitário. O cerceamento do acesso ao mercado pode resultar em privações de demais direitos, esse cerceamento possui uma característica muito marcante, é velado. Restrições a esses direitos não aparecem de forma explícita, elas aparecerem em forma de pequenas dificuldades na concretização da criação do empreendimento próprio. Aparecem na forma de falta de informação, onerosidade excessiva e burocracia desmedida (SEN, 2010, p.43). Em sentido contrário, o raciocínio do autor segue:

$O$ fato de que o direito às transações econômicas tende a ser um grande motor do crescimento econômico tem sido amplamente aceito. Mas muitas outras relações permanecem pouco reconhecidas, e precisam ser mais plenamente compreendidas na análise das políticas. $O$ crescimento econômico pode ajudar não só elevando rendas privadas, mas também possibilitando ao Estado financiar a seguridade social e a intervenção governamental ativa. Portanto, a contribuição do crescimento econômico tem que ser julgada não apenas pelo aumento da renda privada, mas também pela expansão de serviços sociais (incluindo, em muitos casos, redes de segurança social) que o crescimento econômico pode possibilitar (SEN, 2010, p. 61).

O desenvolvimento local é a ideia de determinar qual o potencial de recursos com que se conta bem como quais as necessidades pessoais, de comunidades, das 
coletividades, dos municípios ou de qualquer forma de organização social. Para que ele seja alcançado é preciso determinar qual é o potencial dos recursos disponíveis, tanto qualitativamente quando quantitativamente, bem como delimitar os objetos da ação (LIRA; ESCUDERO, 2012, p. 11).

As peculiaridades territoriais de uma determinada localidade são fundamentais para a elaboração de estratégias que viabilizem a exploração dos recursos endógenos daquela localidade. A delimitação territorial torna-se imprescindível para e eficiência dos investimentos públicos em determinado programa social (LIRA; ESCUDERO, 2012, p. 8).

A topografia do ambiente não é fator único para o desenvolvimento de determinada região, porém como as dificuldades topográficas serão superadas, deve ser alvo de ponderação no momento de formulação da estratégia. A estratégia deve levar em conta, segundo o método de Lyra e Escudero, outros fatores como:

\begin{abstract}
Determinação de objetivos estratégicos a partir do conhecimento do potencial econômico local, análise dos recursos e potencialidades da zona, assim como das principias carências e obstáculos que possam existir para que apareçam e se desenvolvam atividades econômicas; criação dos meios que envolvam a todos os agentes econômicos neste processo. Trata-se neste caso, de introduzir a dinâmica e a estrutura do associativismo (parceria) e de cooperação em torno a uma instituição de seguimento e ajuda às iniciativas e ações de desenvolvimento; criação de condições gerais e infraestrutura adequada para permitir e facilitar o surgimento das iniciativas econômicas tendo em conta as necessidades detectadas e os objetivos perseguidos, criando assim um ambiente favorável para as empresas e negócios. Aqui, deve-se incorporar também tudo o que tem que ver com a infraestrutura social que deve oferecer o município; medidas de acompanhamento relacionadas com a formação dos recursos humanos às demandas do mercado de trabalho que surjam, informação contínua de quais são e como utilizar os programas de promoção do desenvolvimento lançados por qualquer nível institucional e, sobretudo, melhorar os aspectos que possam afetar as potencialidades de desenvolvimento; medidas de acompanhamento relacionadas com programas de índole social, subsídios específicos e aspectos relacionados aos setores de saúde e educação (LIRA; ESCUDERO, 2012, p. 11).
\end{abstract}

Objetivos estratégicos bem delineados se mostram imprescindíveis para o bom andamento da política pública. Os obstáculos levantados em face do avanço econômico também devem ser mensurados, bem como o fomento econômico propiciado pela iniciativa privada (LIRA; ESCUDERO, 2012, p. 13).

A Constituição da República de 1988 traz no artigo 170 os princípios direcionadores da ordem econômica brasileira. Esses primados constitucionais 
demonstram a tamanha relevância que o legislador atribuiu quando elencou princípios que direcionassem a ordem econômica nacional. A ordem econômica está diretamente ligada ao desenvolvimento das políticas públicas, uma vez que o nossa Constituição estabelece um estado prestador de serviços sociais, característico de um modelo de estado de bem-estar social.

\section{CONSIDERAÇÕES AO NEOLIBERALISMO}

No que se refere ao desenvolvimento social, algumas políticas nacionais de cunho neoliberais se propagam e espalham o que teoricamente é incompreensível devido as suas características. Primeiramente, o neoliberalismo não possui um corpo teórico delineado e coerente. A fundamentação dessa teoria se baseia no liberalismo, porém possui traços do conservadorismo, o que chega mesmo a afastar das vertentes liberais do século XX (DRAIBE; RIESCO, 2007, p. 87). Em segundo lugar, as posições neoliberais não são originais, o que leva a constantes modificações. Essas modificações se situam principalmente quanto às responsabilidades públicas nos campos da educação, combate à pobreza, desenvolvimento de novas tecnologias, ampliação da competitividade das economias nacionais (DRAIBE; RIESCO, 2007, p. 87). Finalmente, o neoliberalismo não se alimenta da mesma fonte teórica que em tese deveria se valer, ao contrário, encontra-se quando neoliberais se valem de ideias democratas ou socialistas apagando sua origem e se apropriando delas como se deles fosse. Essa estratégia leva a uma dominação ideológica, uma vez que qualquer forma de modernização social e política se torna é reclamada por neoliberais, ao que não procede. $O$ neoliberalismo atual não se baseia em obras intelectuais de reconhecida competência (DRAIBE; RIESCO, 2007, p. 88).

De fato suas proposições são sobretudo práticas e enraizadas em algumas afirmações de valores que passaram a retrata-lo. Desde logo, está a referência a ideias e não a interesses: afirmando recusar a tese liberal da política pluralista ou conduzida pelos jogos de interesses através de seus advogados e lobbies, mas também pretendo superar mecanismos políticos típicos da vida democrática, o tecnocratismo neoliberal declara-se atuar movido por ideias e valores distantes e acima dos particularismos, corporativismos e populismo de toda a ordem, forma de redução do interesse geral a algumas concepções do que seja "moderno", "flexível" e "eficiente" (DRAIBE; RIESCO, 2007, p. 88). 
Essa ideologia se fundamenta na redução do estado, o mercado constitui o melhor e mais eficiente mecanismo de alocação de recursos. $A$ priori, essa premissa é incompatível com a Constituição da República de 1988, sendo contrária as máximas do princípios elencados no artigo 170, quais sejam: soberania nacional, propriedade privada, função social da propriedade, livre concorrência, defesa do consumidor, defesa do meio ambiente, inclusive mediante tratamento diferenciado conforme o impacto ambiental dos produtos e serviços e seus processos de elaboração e prestação, redução das desigualdades regionais e sociais, busca do pleno emprego, tratamento favorecido para as empresas de pequeno porte constituídas sob as leis brasileiras e que tenham sua sede e administração no país.

Talvez a maior batalha travada pelos neoliberais seja a contraposição ao modelo de estado de bem-estar social. A grande crítica feita pelos neoliberais à concepção keynesiana é a intervenção estatal no domínio econômico adotado por estes e refutado por aqueles. Oposto ao estado neutro, para os neoliberais, o estado é mínimo e usam, como argumento, teses e movimentos de mobilização de mecanismos pseudounificadores presentes da comunidade, no espírito nacional, revitalização conservadora, em que se situa a "modernização" das instituições. Quanto aos programas sociais, propostas de reformas surgem a todo momento. Esses são considerados uma ameaça às liberdades individuais, inibem a atividade privada e geram indesejados controles burocráticos (DRAIBE; RIESCO, 2007, p. 89).

\footnotetext{
Não podemos deixar de lembrar que, afinal, as políticas e programas do Estado de bem-estar social vieram corrigir situações de desigualdade, pobreza e perda de renda, exatamente aquelas tipicamente geradas pela economia de mercado, nas suas "naturais" oscilações e crises. Por outro lado, as economias maduras, assentadas sobre os modos fordistas e neofordistas de produção, tiveram, entre as bases de sustentação de seu crescimento e da ampliação do consumo de massas, o fundo público mobilizado pelos programas sociais. Nas suas primeiras versões, as propostas neoliberais para as políticas sociais repetiram sem crítica ou alterações, mas com uma certa dose de cinismo, os anacronismos e as limitações dos liberais de primeira hora (DRAIBE; RIESCO, 2007, p. 92).
}

O neoliberalismo passa por mudanças significativas a partir dos anos 70. Em primeiro momento, sua orientação era superar a crise pela negação dos princípios sociodemocratas de regulação econômico-social. No segundo momento, acentuou a crença em políticas de crescimento que apoiassem a competição sistêmica como foco em mecanismos de modernização e flexibilização das estruturas e fatores sociais, 
desde que condizentes com as características das novas tecnologias. As mudanças também avançaram no âmbito das políticas sociais. Passou a dar ênfase, no momento de maior acentuação da crise, no corte de gastos em programas sociais, sua completa extinção ou a redução do papel estatal nas políticas sociais (DRAIBE; RIESCO, 2007, p. 93).

Quanto à agenda de reformas dos programas sociais pelos neoliberais, alguns exemplos se colocam em pauta de análise. A primeira delas é o imposto negativo sobre a renda mínima garantida. A crítica neoliberal se dá na forma estatizada de produção e operação de serviços sociais. Esse plano tem por intenção a substituição de parte dos bens e serviços sociais por uma alocação direta de recursos em dinheiro. Para os neoliberais e conservadores, a renda mínima expressa a concepção do estado em atender as necessidades básicas. O estado somente ofereceria a renda mínima de modo residual, complementando o que mercado, família ou comunidade não tenha atendido. Vale ressaltar que essa política assistencial é limitada a um teto máximo (DRAIBE; RIESCO, 2007, p. 94).

\begin{abstract}
Ainda que no plano ideológico, a justificativa da forma dinheiro para alocação da renda mínima municia-se de argumentos do ideal libertário e autonomista contemporâneo que, criticando os modos burocratizados, tuteladores, controladores, hierarquizados e autoritários de operação dos serviços sociais estatais, sugerem uma ampliação da liberdade dos indivíduos e das famílias para buscarem a alternativa de serviço social que Ihes aprouver, uma vez previamente financiados pelo estado através daqueles recursos em espécie. É principalmente no campo dos "serviços sociais pessoais", como por exemplo a guarda de crianças pequenas ou o cuidado com idosos, inevitavelmente atravessados por laços afetivos, ou no campo de serviços que, por sua natureza, são distribuídos discretamente, que tal argumentação vem encontrando desenvolvimento. Garantida a "gratuidade" dos serviços - um vez que se mantém o financiamento público distribuído sob a forma de recursos em dinheiro - estariam os indivíduos e as famílias livres para escolherem as prioridades, as formas e os tipos de serviços que thes parecerem os mais necessários e convenientes, "comprando-os" onde estiverem e de que quem, sob sua perspectiva, melhor os vender (DRAIBE; RIESCO, 2007, p. 93).
\end{abstract}

Descentralizar, privatizar e concentrar os programas sociais públicos nas populações ou grupos carentes, esses parecem ser os objetivos das reformas neoliberais. A descentralização é concebida como um modo de aumentar a eficiência e eficácia dos gastos públicos, uma forma de aumentar a interação dos recursos públicos em nível local (DRAIBE, 2007, p.97). A focalização significa o direcionamento dos recursos para públicos específicos. A justificativa para esses 
argumentos são o de que o estado deve entrar apenas de forma residual e somente no campo da assistência social e o segundo argumento é o de que "os necessitados não são, em princípio, os que efetivamente se beneficiam do gasto social" (DRAIBE; RIESCO, 2007, p. 97).

A privatização, entendida como deslocamento dos bens e serviços públicos para o setor privado, vem como solução para a crise fiscal. A privatização se estende também à transferência de meios de produção, bem como distribuição de bens e serviços para o setor privado ou a entidades não governamentais sem fins lucrativos (DRAIBE; RIESCO, 2007, p. 97).

O neoliberalismo não se preocupa com a justiça social. Fato é que reformas com intenção de redirecionar gastos sociais, definidas em sede de crise econômica, altas taxas de desemprego e queda da renda revivem um problema antigo, a pobreza. Em se tratando de pobreza, o tema justiça social na orientação de políticas públicas é de altíssima relevância. A redução de recursos e gastos com programas sociais contradiz o que o próprio argumento neoliberal de que haveria ampliação dos direitos sociais através da universalização de programas e a multiplicação de políticas não contributivas (DRAIBE; RIESCO, 2007, p. 98).

Ao reduzir os recursos públicos e privados disponíveis para o gasto social, exigem também opções, seleção de políticas e prioridades a alguns de seus beneficiários, o que teoricamente contradiz a tendência à universalização anteriormente afirmada. Em outras palavras, é também no espaço da concepção distributiva da justiça que se arma os argumentos dos oponentes do neoliberalismo de que o gasto público e as políticas sociais, para ganharem força redistributiva e compensatória da desigualdade social, devem privilegiar as camadas mais pobres da população. Em face das já existentes desigualdades e do agravamento da pobreza, é como se estivéssemos passando de uma concepção do tipo "dar tudo cada vez mais a todos" - uma forma de expressar a visão universalista, associada ao direito social - à expressão " dar mais a quem tem menos" modo de exprimir prioridades à população carente, seletivamente escolhida pelo foco das políticas e dos programas sociais (DRAIBE; RIESCO, 2007, p. 98).

A américa latina conheceu várias fórmulas que se propuseram proporcionar o desenvolvimento social, políticas públicas ambiciosas ao ponto de propor erradicação da pobreza e até mesmo auxilio emergencial aos pobres (DRAIBE; RIESCO, 2007, p.101). O fato é que se observa um acentuado processo de deterioração dos serviços públicos e empobrecimento da população. Quanto às reformas neoliberais, essas se mostram simplistas e incoerentes. Ao mesmo tempo que se propõe a reagir de forma 
eficaz e eficiente em sede de crise socioeconômica, não possuem embasamento fundamentação científica alguma. O que as faz perdurar é o fato de que são uma alternativa ao modelo vigente, mesmo não possuindo eficácia comprovada.

\section{CONSIDERAÇÕES FINAIS}

O processo de desenvolvimento econômico através das políticas públicas ainda está um tanto quanto distante de sua concretização. Com o advindo da Constituição do Brasil de 1988, observa-se um avanço nos direitos fundamentais e o combate à desigualdade social.

O estudo das políticas públicas demonstra que um maior delineamento do projeto, o qual se pretende desenvolver na sociedade é de suma importância. As fases das políticas públicas, apesar do não consenso quanto às suas divisões, traçam o planejamento que o ente público deve respeitar. Não menos importante, outros fatores estão envolvidos no processo de desenvolvimento de uma determinada localidade, atores públicos e privados agindo no interesse do bem comum efetivam o que o legislador da Constituição Pátria de 1988 pretendeu como objetivo a ser alcançado pela nação.

O caminho a ser percorrido na busca pela diminuição das desigualdades sociais, traçado por meio das políticas públicas, não pode ficar preso em ideologias que, como efetividade, não possui comprovação, bem como teoria não possui corpo delimitado. A pobreza e a miséria são crescentes frente a ideias de diminuição do papel do estado em políticas prestacionais. Não menos importante, essas ideias são incompatíveis com os preceitos constitucionais e seus direcionamentos. 0 artigo $6^{\circ}$ da Constituição do Brasil de 1988 é enfático em garantir direitos sociais como educação, saúde, alimentação, trabalho, moradia, transporte, lazer, segurança, previdência social, proteção à maternidade e à infância e assistência aos desamparados, sendo qualquer reforma que pretenda abolir esses direitos é, no mínimo, atentatória a conquistas históricas e sociais.

O mercado, apesar de sua indiscutível importância ao desenvolvimento de determinada região, não aloca de forma eficiente os recursos, pois não é de fundamental interesse dele. A iniciativa privada possui um único interesse e sua 
função social só foi estabelecida historicamente através de conquistas sociais. Os direitos sociais são conquistas históricas e as constituições sociais sintetizam esse sentimento.

Em suma, o mercado por natureza não consegue atender as demandas sociais assim como é proposto pelas teorias neoliberais. Primeiramente é importante destacar a importância do estado como mediador das relações sociais. O surgimento do estado não advém das relações comerciais (assim como propõe a teoria liberal clássica), o surgimento do estado é histórico. Sua existência fundamenta e estrutura as relações de mercado e essa afirmação se evidencia em inúmeras crises do estado moderno e o "socorro" prestado ao mercado pelo estado. Portanto, a mitigação do papel do estado enquanto tutor dos direitos sociais e mantenedor das relações econômicas equivale a mitigar a base que estrutura as relações sociais e econômicas. O caminho a ser percorrido na busca do desenvolvimento social e econômico deve passar, primeira e obrigatoriamente, pelo cumprimento dos preceitos sociais a que a Constituição do Brasil de 1988 se propõe.

\section{REFERÊNCIAS}

ACEMOGLU, Daron; ROBINSON, James. Por que as nações fracassam: as origens do poder, da prosperidade e da pobreza. São Paulo: Elsevier, 2012.

ARRETCHE, Marta. Democracia e redução da desigualdade econômica no Brasil: a inclusão dos outsiders. Revista Brasileira de Ciências Sociais, São Paulo, v. 33, n. 96 , p. $1-23,2018$.

ARRETCHE, Marta T. S. Emergências e Desenvolvimento do Walfare State: teorias explicativas. Revista Brasileira de Informação Bibliográfica em Ciências Sociais, Rio de Janeiro, n. 39, p. 3-40, 1. sem. 1995. Disponível em: https://www.anpocs.com/index.php/bib-pt/bib-39/452-emergencia-edesenvolvimento-do-welfare-state-teorias-explicativas/file. Acesso em: 22 jun. 2020.

BRASIL. [Constituição (1988)]. Constituição da República Federativa do Brasil. Brasília, DF: Presidência da República, 2016. Disponível em: http://www.planalto.gov.br/ccivil_03/constituicao/constituicao.htm. Acesso em: 01 set. 2019.

BRASIL. Ministério da Educação. Relatório educação para todos no Brasil: 2000-2015: versão preliminar. [S. I.], jun. 2014a. Disponível em: http://portal.mec.gov.br/index.php?option=com_docman\&view=download\&alias $=15$ 774-ept-relatorio-06062014\&Itemid=30192. Acesso em: 02 set. 2019. 
BRASIL. Ministério da Saúde. Secretaria de Vigilância em Saúde. Departamento de Análise de Situação em Saúde. Saúde Brasil 2013: uma análise da situação de saúde e das doenças transmissíveis relacionada a pobreza. Brasília: Ministério da Saúde, 2014b. Disponível em:

http://bvsms.saude.gov.br/bvs/publicacoes/saude_brasil_2013_analise_situacao_sa ude.pdf. Acesso em: 03 set. 2019.

DRAIBE, Sônia; RIESCO, Manuel. Estado de bem-estar, desenvolvimento econômico e cidadania: algumas lições da literatura contemporânea. In: HOCHMAN, Gilberto; ARRETCHE, Marta; MARQUES, Eduardo (Org.). Políticas Públicas no Brasil. Rio de Janeiro: Ed. Fiocruz, 2007.

HAM, Christopher; HILL, Michael. O processo de elaboração de políticas no estado capitalista moderno $=$ The policy process in the modern capitalist state. 2 . ed. Tradução: Renato Amorim e Renato Dagnino. Adaptação e Revisão: Renato Dagnino. Campinas: GAPI-DPCT-UNICAMP, 1993. Disponível em: https://ainterpol.files.wordpress.com/2014/05/texto-iepp-processo-de-elaboracao-depoliticas-no-estado-capitalista-moderno-hill.pdf. Acesso em: 22 jun. 2020.

IBGE. Alfabetização 2013. [S. /.]: IBGE, c2020b. Disponível em: https://atlasescolar.ibge.gov.br/images/atlas/mapas_brasil/brasil_alfabetizacao.pdf. Acesso em: 09 nov. 2018.

IBGE. Rendimento 2013. [S. I.]: IBGE, c2020a. Disponível em: https://atlasescolar.ibge.gov.br/images/atlas/mapas_brasil/brasil_rendimento.pdf. Acesso em: 09 nov. 2019.

LIRA, Iván Silva; ESCUDERO, Carlos Sandoval. Metodologia para elaboração de estratégias de desenvolvimento local. Santiago: CEPAL, 2012. Santiago, Chile.

SECCHI, Leonardo. Políticas Públicas: conceito, esquema de análise, casos práticos. 2. ed. São Paulo: Cengage Learning, 2017.

SEN, Amartya. A Ideia de Justiça. Companhia das Letras. São Paulo: 2011.

SEN, Amartya. Desenvolvimento como Liberdade. Tradução Laura Teixeira Motta; revisão técnica Ricardo Dominelli Mendes. Companhia das Letras. São Paulo: 2010.

TRADING ECONOMICS. Brasil: PIB: Taxa de crescimento a nual. [S. l: s. n.], c2020. Disponível em: https://pt.tradingeconomics.com/brazil/gdp-growth-annual. Acesso em: 07 nov. 2018. Gráfico dinâmico. Necessária pesquisa do período de jul. 2015 a jul. 2018 para visualização dos resultados pesquisados. 